REVIEW

\title{
Acute poisoning: understanding $90 \%$ of cases in a nutshell
}

\author{
S L Greene, P I Dargan, A L Jones
}

Postgrad Med J 2005;81:204-216. doi: 10.1136/pgmj.2004.024794

The acutely poisoned patient remains a common problem facing doctors working in acute medicine in the United Kingdom and worldwide. This review examines the initial management of the acutely poisoned patient. Aspects of general management are reviewed including immediate interventions, investigations, gastrointestinal

decontamination techniques, use of antidotes, methods to increase poison elimination, and psychological assessment. More common and serious poisonings caused by paracetamol, salicylates, opioids, tricyclic antidepressants, selective serotonin reuptake inhibitors, benzodiazepines, non-steroidal anti-inflammatory drugs, and cocaine are discussed in detail. Specific aspects of common paediatric poisonings are reviewed.

See end of article for authors' affiliations

Correspondence to: Dr S Greene, Medical Toxicology Unit, Avonley Road, New Cross, London SE14 5ER, UK; Shaun. Greene@gstt.nhs.uk

Submitted 28 May 2004 Accepted 4 August 2004
A lthough the overall severity of poisoning in the UK has decreased over the past 10 years the number of poisoned patients presenting to emergency departments (EDs) is increasing, accounting for $5 \%-10 \%$ of an $\mathrm{ED}^{\prime} \mathrm{s}$ workload. ${ }^{1-3}$ Rates of self poisoning in the UK are among the highest in Europe. ${ }^{4}$ Provision of meticulous supportive care, identification of patients requiring treatment with an antidote, and the appropriate use of methods limiting poison absorption or increasing elimination, remain the cornerstones of management. This article will focus on the initial general management of the poisoned patient and examine more specific issues in the management of the most common and serious poisonings.

\section{EPIDEMIOLOGY}

Accidental poisoning accounts for about 80000 annual ED attendances in England and is most common in children under 5 years of age, although most do not develop significant clinical features. ${ }^{6}$ There are about 1000 deaths each year in the UK from accidental poisoning, predominantly in adults with $50 \%$ of cases attributable to opioid poisoning. ${ }^{7}$ ED attendances in the UK after intentional self poisoning (347 per 100000 ) are increasing and result in more than 2000 deaths each year, however only $29 \%$ of all intentional self poisoning deaths occur in hospital. $^{5}$ Poisoned patients account for $10 \%$ of admissions to general medical wards. $^{8}$ Iatrogenic poisoning caused by prescribing/ administration errors or unrecognised adverse drug interactions has recently been identified as a significant problem, and these account for about $1 \%$ of calls to the National Poisons Information Service (NPIS), London.
Paracetamol remains the most common drug taken in overdose in the UK $(50 \%$ of intentional self poisoning presentations). ${ }^{19}$ Non-steroidal anti-inflammatory drugs (NSAIDs), benzodiazepines/zopiclone, aspirin, compound analgesics, drugs of misuse including opioids, tricyclic antidepressants (TCAs), and selective serotonin reuptake inhibitors (SSRIs) comprise most of the remaining $50 \%$ (box 1). Reductions in the price of drugs of misuse have led to increased cocaine, MDMA (ecstasy), and $\gamma$-hydroxybutyrate (GHB) toxicity related ED attendances. ${ }^{10}$ Clinicians should also be aware that severe toxicity can result from exposure to non-licensed pharmacological or common environmental agents including plants, herbal and traditional remedies, industrial chemicals, heavy metals, and animal bites or stings.

\section{GENERAL MANAGEMENT}

Serious clinical effects occur in less than $5 \%$ of acutely poisoned patients. ${ }^{5}$ Overall in-hospital mortality rates are less than $0.5 \% .^{5}$ Most poisoned patients can be treated with supportive care during an appropriate period of observation. The challenge for the attending clinician is to identify as early as possible patients who are at risk of developing serious clinical toxicity, and who may benefit from decontamination or a specific intervention.

Recent high profile terrorist activities have highlighted the need for ED decontamination facilities and the availability of appropriate antidotal therapy. ${ }^{11}{ }^{12}$ Poisoned patients who may contaminate others must be identified early and decontaminated appropriately before treatment. ED staff must be trained to use protective clothing, breathing apparatus, and decontamination facilities.

Internet based information services such as Toxbase (http://www.spib.axl.co.uk) and Isabel (http://www.isabel.org.uk) aid triage staff in identifying patients who may benefit from immediate intervention (for example, the administration of activated charcoal). Product information leaflets and older textbooks are often out of date and are not a reliable source of information in managing poisoned patients. The NPIS is a telephone based (0870 6006266$)$

Abbreviations: ED, emergency department; NPIS, National Poisons Information Service; TCA, tricyclic antidepressant; NSAID, non-steroidal anti-inflammatory drug; IV, intravenous; IM, intramuscular; CNS, central nervous system; $A C$, activated charcoal; $G \mathrm{G}$,

gastrointestinal; MDAC, multidose activated charcoal; ALF, acute liver failure; NAC, N-acetylcysteine; LFT, liver function test; $\mathrm{MI}$, myocardial infarction; SSRI, selective serotonin reuptake inhibitor; $\mathrm{ACS}$, acute coronary syndrome 
resource available to all healthcare professionals. The NPIS provides 24 hour on call cover by clinical toxicologists.

\section{IMMEDIATE CARE}

Treatment of cardiac arrest in the poisoned patient should generally follow ACLS guidelines, however there are circumstances in which different approaches are required (for example, early use of hypertonic sodium bicarbonate in cardiac arrest associated with TCA poisoning). ${ }^{13}$

The initial priority in treating seriously ill poisoned patients is standard resuscitation-that is, airway, breathing, and circulation. Inadequate ventilation caused by airway compromise or reduced respiratory effort may require an oropharyngeal or nasopharyngeal airway and bag-mask ventilation with the provision of supplemental oxygen until a definitive airway can be obtained, either through toxin reversal (for example, naloxone for opioids), or rapid sequence induction, intubation, and mechanical ventilation. ${ }^{14}$

Hypotension should be treated initially using intravenous (IV) fluids (an initial bolus of $10-20 \mathrm{ml} / \mathrm{kg}$ of crystalloid titrated to clinical effect). Hypotension produced by poisons such as opioids, $\beta$ blockers, or digoxin can in addition be treated using the specific antidote (that is, naloxone, glucagon, and digoxin specific antibodies respectively). Hypotension resistant to treatment with IV fluids or appropriate antidotes is managed by measuring central venous pressure to ensure adequate circulatory filling and then cautious administration of an appropriate inotropic agent. Norepinephrine (noradrenaline) should be considered in poisonings producing peripheral vasodilatation whereas adrenaline is likely to be more effective where there is direct toxin related myocardial depression. ${ }^{15}$ The use of inotropic agents may worsen cardiovascular toxicity and should generally be discussed with a clinical toxicologist.

Arrhythmias associated with poisoning should generally not be treated with antiarrhythmic drugs as a first line approach. Most antiarrhythmic agents have the potential to be pro-arrhythmic and negatively inotropic and so indiscriminate use of these agents in poisoned patients is inadvisable. Factors precipitating or contributing to the arrhythmia such as acidosis, hypokalaemia, hypomagnesaemia, and hypoxia should be corrected..$^{15}$ It is preferable to use specific measures rather than administering antiarrhythmic agents, for example, hypertonic sodium bicarbonate for TCA related arrhythmias, digoxin specific antibodies for digoxin related arrhythmias, and overdrive pacing for ventricular tachyarrhythmias. ${ }^{13}{ }^{15}$ Correction of precipitating factors and the appropriate use of antidotal agents negates the need for

Box 1 Most common drug ingestion inquiries to London Poisons Information Service (2002)

- Paracetamol

- Ibuprofen

- Aspirin

- Diazepam

- Drugs of misuse

- Zopiclone

- Fluoxetine

- Paroxetine

- Coproxamol

- Temazepam

- Codeine

- Amitriptyline antiarrhythmic agents in most cases. Electrical cardioversion may produce asystole in the presence of a poisoned myocardium and should only be used after correction of acidosis, metabolic, abnormalities, and hypoxia, and the appropriate use of antidotal agents (particularly sodium bicarbonate in TCA poisoning). Electrical cardioversion is appropriate treatment in conjunction with the above measures in cases of pulseless VT and cardiac arrest according to ACLS guidelines. ${ }^{13}$

Sustained seizures should be treated using benzodiazepines (lorazepam $4 \mathrm{mg}$ IV or IM, or diazepam 5-10 mg IV/PR initially). ${ }^{16}$ It is important that a bedside blood sugar concentration (BM) is checked early in any patient with seizures to exclude hypoglycaemia as a cause. The sodium channel blocking properties of phenytoin can theoretically exacerbate the cardiotoxicity of some drugs such as cocaine and TCAs, and thus should be avoided in treating seizures secondary to these drugs. ${ }^{17}$ Resistant seizures should be treated with general anaesthetic sedation (IV barbiturates) and supportive care (intubation and mechanical ventilation, with EEG monitoring). ${ }^{15}$

Agitated patients requiring sedation should be treated with IV benzodiazepines, 5-10 $\mathrm{mg}$ of diazepam or 2-4 $\mathrm{mg}$ of lorazepam IV are appropriate initial doses. Lorazepam may be administered intramuscularly (IM) but is more difficult to titrate via this route. Large doses are often required but should be administered in increments $(5 \mathrm{mg}$ of diazepam or $2 \mathrm{mg}$ of lorazepam every three to five minutes until appropriate sedation is achieved) to avoid excessive central nervous system (CNS) and respiratory depression. ${ }^{15}$ Phenothiazines or butyrophenones can increase toxicity of cardiotoxic drugs and reduce the seizure threshold and so are best avoided in the treating the agitated poisoned patient. ${ }^{18-21}$

Significant hypoglycaemia should be treated initially with a bolus of $50 \mathrm{ml} 50 \%$ IV dextrose. ${ }^{22}$ Insulin related hypoglycaemia may be prolonged and require a $10 \%-20 \%$ dextrose infusion carefully titrated against the blood glucose concentration, with close monitoring for possible electrolyte disturbances, particularly hypokalaemia. ${ }^{22}$ Sulphonylurea and meglitinide induced hypoglycaemia should initially be treated with a boluses of dextrose ( $50 \mathrm{ml}$ of $50 \%$ IV dextrose) followed by the administration of oral carbohydrates after initial euglycaemia is achieved. Continued hypoglycaemia should be treated using octreotide (50 $\mu$ g SC 8-12 hourly), which decreases IV dextrose requirements and therefore minimises the risk of glucose stimulated insulin release. ${ }^{23}$

Naloxone can be safely used as a diagnostic tool in unconscious patients. ${ }^{24}$ The appropriate use of naloxone is discussed later in this article. Patients with a history of alcohol misuse at risk of Wernicke's encephalopathy should receive $100 \mathrm{mg}$ of IV thiamine, followed by an oral preparation. ${ }^{25}$

Patients with core temperatures of greater than $39.0^{\circ} \mathrm{C}$ should be treated aggressively with cool IV fluids and active cooling measures because prolonged hyperthermia can result in significant complications such as rhabdomyolysis, acute renal failure, and disseminated IV coagulation. ${ }^{26-29}$ Intravenous benzodiazepines are appropriate treatment in hyperthermic patients with evidence of excessive sympathetic stimulation such as that associated with cocaine and amphetamines..$^{21} 30$ Patients with resistant hyperthermia should be discussed with a clinical toxicologist. They may benefit from peripherally acting muscle relaxants (dantrolene), centrally acting serotonin antagonists (cyproheptadine), or general anaesthetic sedation. ${ }^{31} 32$

\section{INVESTIGATIONS}

All acutely poisoned patients should have their heart rate, blood pressure, respiratory rate, and temperature recorded. 
An ECG may detect occult cardiac conduction abnormalities of diagnostic and prognostic importance. Estimation of patient weight by medical and nursing staff is often inaccurate and leads to treatment errors both in the estimation of the toxic dose of drugs ingested by patients and the dose of drugs administered in treatment. ${ }^{33}$ Patients should undergo formal weight measurement as part of routine clinical care. ${ }^{33}$

All unconscious patients and those with features of severe toxicity (seizures, hypotension, cardiac arrhythmias, or respiratory depression) should have measurement of electrolytes, renal function, paracetamol concentration, and determination of acid-base status via a venous bicarbonate concentration or arterial blood gas analysis. ${ }^{15}$

Paracetamol concentration should be measured in all patients who present after overdose, particularly those who are unconscious or who are unable to give a reliable history. ${ }^{34}{ }^{35}$ Paracetamol poisoning is potentially lethal but can be detected and treated during the initial asymptomatic phase. It is important to remember that paracetamol may not be detected if the patient's presentation is delayed greater than 18 hours after overdose. In these cases clinicians should look for clinical and biochemical evidence of paracetamol toxicity. Patients without clinical features suggestive of salicylate poisoning (that is, tinnitus, sweating, changed conscious level, tachypnoea, metabolic acidosis) do not require routine measurement of salicylate concentrations. ${ }^{36}$

Bedside urine drug test kits are generally not helpful in managing acutely poisoned patients. They are non-specific and do not provide reliable information regarding time of drug exposure. ${ }^{37}$ For example, a patient testing positive for metabolites of cocaine may have been exposed to the drug five days previously and have no significant acute toxicity. ${ }^{38}$

Measurement of plasma drug concentrations is not routinely helpful in treating poisoned patients and should not be part of clinical care. ${ }^{39}$ Exceptions include paracetamol, salicylates, iron, lithium (especially in the presence of impaired renal function), theophylline, ethylene glycol, ethanol (when used as an antidote for ethylene glycol or methanol poisoning), and methanol and to a lesser extent digoxin, phenobarbitone, sodium valporate, and carbamazepine. ${ }^{40}$ Most plasma drug concentrations do not correlate with observed clinical toxicity. Results of toxicology drug screens are rarely available rapidly enough and do not have a significant impact on patient management. ${ }^{41}$ Most poisoning should be treated on the basis of observed clinical toxicity rather than drug concentration.

Toxicology screens may be appropriate in the medicolegal management of poisoned patients or if there is a suspicion of child abuse. Requests for urgent urine or blood toxicology screens should be discussed with a clinical toxicologist to make them as complete and relevant as required.

Patients who present alleging they have been the victim of a sexual assault after having their drink "spiked" should have biological samples taken in the ED for toxicological analysis only if the contaminated drink was ingested very recently. Common drugs used in date rape (GHB, midazolam) can only be detected in a urine or blood sample obtained within the first few hours of exposure. ${ }^{42}$

\section{GUT DECONTAMINATION}

The role of gut decontamination procedures is outlined in a series of consensus statements published by the American Academy of Clinical Toxicologists (ACCT) and European Association of Poison Centres and Clinical Toxicologists (EAPCCT) ${ }^{43-47}$

Activated charcoal (AC) is a safe and probably effective agent used to decrease the amount of drug absorbed from the gastrointestinal (GI) tract into the bloodstream. Data supporting the use of AC are extrapolated from volunteer studies and there is a paucity of well controlled data from clinical studies. ${ }^{43}$ However, the position statement recommends that AC should be considered as a $50 \mathrm{~g}(\mathrm{lg} / \mathrm{kg}$ in children) oral dose for patients who have ingested a potentially toxic overdose within the previous hour. Only $10 \%-15 \%$ of patients are seen within an hour of ingestion and further delays can occur in triage or waiting to see a doctor, therefore it is important that those who present early after a potentially serious overdose are rapidly identified so that AC can be administered. ${ }^{48-50}$ There is little evidence for the effectiveness of AC in reducing GI absorption of toxins if given beyond an hour after ingestion, however it should be considered in large overdoses of toxic drugs where delayed GI absorption is possible (for example, TCAs, sustained release preparations). ${ }^{43} 51$

Activated charcoal is less effective at adsorbing metals (lithium, iron), alcohols (methanol, ethylene glycol), or petroleum distillates (white spirit). ${ }^{52}$ AC causes vomiting in about $5 \%$ of patients. ${ }^{43}{ }^{52}$ AC can be given to unconscious patients after intubation through a large bore nasogastric tube. ${ }^{43}$

Gastric lavage has no role in routine GI decontamination of acutely poisoned patients. There is no evidence that gastric lavage improves patient outcome. ${ }^{46}$ Gastric lavage may even push tablets further into the GI tract, ${ }^{53}$ although a reanalysis of these data has brought this into question. ${ }^{54}$ Vagal stimulation and hypoxia during gastric lavage potentially increases risk of cardiac arrhythmias. ${ }^{55}$ Gastric lavage should only be considered in a patient presenting within one hour of ingestion of a potentially life threatening overdose. ${ }^{46}$ Difficulties of monitoring acutely ill patients during the procedure and the need to maintain airway protection should not be forgotten.

Administration of syrup of ipecac to induce vomiting after acute overdose is not part of accepted clinical care. ${ }^{44}$

Whole bowel irrigation is a newer method of gut decontamination that entails administering polyethylene glycol (2 l/h adults, $500 \mathrm{ml} / \mathrm{h}$ pre-school children) orally until the resulting rectal effluent is clear. ${ }^{47}{ }^{56}$ Case reports and volunteer studies suggest that whole bowel irrigation reduces drug absorption by forcing tablets through the GI tract. ${ }^{47}$ Whole bowel irrigation is used to treat large ingestions of drugs not absorbed by AC (for example, lithium, iron), large ingestions of enteric coated or sustained release tablets (for example, calcium channel blockers), and patients who have ingested packages of illicit drugs to avoid detection at international border crossings (body packers). ${ }^{47}$ Polyethylene glycol is not absorbed and does not produce fluid or electrolyte imbalance. Contraindications to its use include obstructed bowel, ileus, or GI haemorrhage. ${ }^{47}$

\section{ANTIDOTES}

Antidotes are only available for a limited number of drugs and poisons. The most widely used antidotes are $N$ acetylcysteine for paracetamol poisoning and naloxone for opioid poisoning. Table 1 lists some of the other antidotes used in clinical practice. ${ }^{15} 16$

\section{INCREASING ELIMINATION}

Techniques used to increase the elimination of poisons continue to evolve. Patients who may benefit from one of these techniques should be discussed with a poisons unit or clinical toxicologist. Multidose activated charcoal (MDAC) increases the elimination of drugs that undergo enterohepatic or enteroenteric circulation. Evidence to support the effectiveness of MDAC in improving patient outcome is limited to volunteer studies, animal studies, and uncontrolled case reports. ${ }^{45}$ MDAC should be used after potentially toxic 
Table 1 Antidotes used in the management of poisoned patients

\begin{tabular}{|c|c|}
\hline Toxin & Antidote \\
\hline$\beta$ blockers & Glucagon \\
\hline Oral anticoagulants & Vitamin K1 (phytomenadione) \\
\hline Digoxin & Digoxin specific antibodies (Digibind) \\
\hline Ethylene glycol/methanol & Ethanol/4-Methylpyrazole \\
\hline Cyanide & $\begin{array}{l}\text { Thiosulphate/dicobalt ededate/ } \\
\text { hydroxycobalamin }\end{array}$ \\
\hline Organophosphates & Atropine/oximes \\
\hline Iron & Desferrioxamine \\
\hline Heavy metals & EDTA, DMSA, DMPS \\
\hline Paracetamol & $\mathrm{N}$-acetylcysteine \\
\hline Opioids & Naloxone \\
\hline Sulfonylureas & Octreotide \\
\hline Tricyclic antidepressants & Sodium bicarbonate \\
\hline
\end{tabular}

ingestions of theophylline and carbamazepine, and is indicated after life threatening overdoses of dapsone, phenobarbitone, and quinine. MDAC is given as a $50 \mathrm{~g}$ ( $\mathrm{g} / \mathrm{kg}$ in children) dose and repeated four hourly. ${ }^{45}$ When MDAC is used, a cathartic agent such as sorbitol should be given as a single dose with the first dose of AC to decrease the risk of obstruction. ${ }^{45}$

Urinary alkalinisation through administration of IV sodium bicarbonate (one litre of a $1.26 \%$ solution over three hours) effectively increases renal elimination of salicylates and chlorpropamide. ${ }^{57}$ It is used for patients who are significantly poisoned with salicylates (plasma concentration $450-700 \mathrm{mg} / \mathrm{l}$ ) who do not yet meet the criteria for haemodialysis. ${ }^{58}$ IV potassium supplementation (20$40 \mathrm{mmol}$ in each litre of $1.26 \%$ sodium bicarbonate) is necessary to ensure production of an alkaline urine and to combat subsequent renal potassium loss. ${ }^{15}$

Extracorporeal techniques are indicated in only a very limited subset of poisonings and only in patients with serious toxicity. ${ }^{59}$ There is also the potential for significant complications (for example, hypotension, sepsis, air embolism) and they may entail transferring an unstable patient to another hospital. ${ }^{59}$ Therefore the use of extracorporeal techniques should always be discussed with a clinical toxicologist.

Haemodialysis may be considered in life threatening toxicity caused by lithium, ${ }^{60}$ salicylates ${ }^{61}$ theophylline, ${ }^{62}$ methanol, and ethylene glycol. ${ }^{63}{ }^{64}$ Charcoal haemoperfusion may be considered in the treatment of severe toxicity caused by theophylline, carbamazepine, and phenobarbitone, ${ }^{6566}$ particularly in cases where MDAC administration is limited by ileus. ${ }^{45}$

\section{PAEDIATRIC POISONING}

Most paediatric poisoning is accidental in nature and occurs between the ages of $1-5$ years. Less than $1 \%$ of paediatric poisoning is clinically serious and death is rare. ${ }^{6}$ However, some drugs including methadone, TCAs, iron, theophylline, antihistamines, methylsalicylate, phenothiazines, quinine/ chloroquine, calcium channel blockers, essential oils, and MDMA can cause severe toxicity after very small ingestions. ${ }^{67-69}$ Although treatment of paracetamol poisoning in the paediatric patient currently follows adult guidelines there is some evidence to suggest that paracetamol is less hepatotoxic in children, ${ }^{70-73}$ the toxic dose being $200 \mathrm{mg} / \mathrm{kg}$ $(150 \mathrm{mg} / \mathrm{kg}$ in adults), however if there is any doubt regarding the dose of paracetamol ingested a plasma paracetamol concentration should be obtained.

Button batteries are commonly ingested by children. ${ }^{74}$ Systemic toxicity is rare; however localised mucosal ulceration with subsequent gastrointestinal haemorrhage or per- foration may occur if the battery remains in the oesphagus or stomach. ${ }^{74-76}$ Batteries that have passed beyond the pylorus are unlikely to cause toxicity unless gastrointestinal transit is delayed resulting in battery corrosion and leakage of contents. ${ }^{74}$ Batteries identified on plain film within the oesphagus should be removed endoscopically. ${ }^{77}$ A patient with a battery within the stomach should be admitted for observation and repeat plain films at $24-48$ hours. Batteries remaining in the stomach after 48 hours should be removed endoscopically. ${ }^{78}$ Children in whom the battery has moved beyond the pylorus can be discharged home with repeat abdominal plain films every 48 hours to ensure the battery remains intact and is passed. ${ }^{79}$

Nearly one third of children under the age of 6 years who present after accidental poisoning will subsequently experience a second episode..$^{80}$ Providing poison prevention education to parents at the time of the first presentation is an important method of reducing the number of paediatric poisonings. Evidence suggests that currently ED staff only provide advice to parents regarding the prevention of further poisoning in a minority of cases. ${ }^{81}$

\section{PARACETAMOL}

Paracetamol is the most common drug ingested in overdose in the United Kingdom (50\% of acute poisoning related hospital presentations) and causes about 150-200 deaths a year through acute liver failure (ALF); however ALF only occurs in about $0.6 \%$ of patients presenting with paracetamol overdose. ${ }^{192}$ We have recently produced an evidence based flowchart to guide the management of patients presenting with paracetamol poisoning. ${ }^{83}$

Intravenous $\mathrm{N}$-acetylcysteine (NAC) is the antidote of choice for significant paracetamol poisoning. ${ }^{84}$ It acts as a glutathione donor and is almost $100 \%$ effective in preventing hepatotoxicity and nephrotoxicity if administered within eight hours of a non-staggered toxic paracetamol overdose. ${ }^{85}$ The mechanism of action and efficacy of NAC in late paracetamol poisoning is more controversial. ${ }^{85} 86$

\section{Risk factors}

The hepatotoxic dose of paracetamol is generally accepted as $150 \mathrm{mg} / \mathrm{kg} .{ }^{87-89}$ There are a number of factors that may potentially increase the risk of hepatotoxicity in patients presenting with paracetamol poisoning (table 2). The following "high risk" factors have become established despite the fact that they are based on little substantive evidence; however currently we support their use: (a) conditions that decrease hepatic glutathione stores or ${ }^{90}$ (b) regular use of drugs that induce certain cytochrome p450 microenzymes. ${ }^{92-94}$ A toxic dose of paracetamol in high risk patients is generally considered to be $75 \mathrm{mg} / \mathrm{kg} .{ }^{88}$ Whether or not long term alcohol excess is a risk factor for paracetamol poisoning is controversial, but the balance of evidence is probably against this being the case. ${ }^{95-98}$

AC reduces paracetamol absorbed from the GI tract if given within one hour of non-staggered overdose. ${ }^{43}{ }^{99}$ Ondansetron

Table 2 Risk factors in paracetamol overdose

\begin{tabular}{ll}
\hline $\begin{array}{l}\text { Decreased hepatic } \\
\text { glutathione stores }\end{array}$ & $\begin{array}{l}\text { Induction of cytochrome p450 } \\
\text { microenzymes }\end{array}$ \\
\hline $\begin{array}{l}\text { Anorexia nervosa } \\
\text { Bulimia }\end{array}$ & Phenytoin \\
HIV & Carbamazepine \\
Cystic fibrosis & Rifampicin \\
Malnourishment & Phenobarbitone \\
\hline
\end{tabular}


effectively reduces paracetamol induced vomiting if first line antiemetics fail. ${ }^{100}$

The management of paracetamol poisoning is best categorised depending on whether the patient presents after a single/non-staggered (total ingestion taken over a few minutes) or staggered overdose (ingestion of a number of doses over a prolonged period of time) and whether the patient presents early or late after ingestion. ${ }^{83}$

\section{Early single/non-staggered paracetamol poisoning (less than 15 hours after ingestion)}

Patients are usually asymptomatic or have nausea and vomiting only. Management is guided by a plasma paracetamol concentration (taken at presentation or four hours after ingestion whichever is later) plotted on the Prescott nomogram (fig 1). ${ }^{8388}$ Paracetamol concentrations on or above the curve indicate significant risk of hepatotoxicity and warrant treatment with NAC. High risk patients are treated using the lower time concentration curve in figure 1.

NAC provides almost $100 \%$ protection if given within eight hours of ingestion and so patients presenting within eight hours of a non-staggered ingestion of any amount of paracetamol do not require immediate treatment with NAC. $^{83} 101102$ The decision to administer NAC in this instance can be made on the basis of the paracetamol concentration provided this is obtained within eight hours of ingestion. ${ }^{83}$ NAC should be started immediately in patients presenting after eight hours of a potentially toxic paracetamol ingestion ( $>150 \mathrm{mg} / \mathrm{kg}$ or $>75 \mathrm{mg} / \mathrm{kg}$ if in a high risk group) and in any case where paracetamol concentration will not be available within eight hours of ingestion. ${ }^{83}$ NAC can be withdrawn if the subsequent paracetamol concentration is well below the relevant treatment line on the Prescott nomogram. Paracetamol concentrations obtained within four hours of overdose cannot be interpreted using the nomogram and are not helpful in patient management. It is important to remember that the successful use of the Prescott nomogram to treat paracetamol poisoning is entirely dependent on an accurate knowledge of time zero, the time of ingestion. Clinicians must use the maximum probable period since time of ingestion to avoid treatment failure through inappropriate non-use of NAC.

\section{Late single/non-staggered paracetamol poisoning (more than 15 hours after ingestion)}

These patients have a greater risk of developing hepatotoxicity because of the reduced efficacy of NAC. ${ }^{102}$ Any patient who presents after ingestion of a potentially hepatotoxic dose of paracetamol should be given NAC and blood should be taken for a plasma paracetamol concentration, INR, liver function tests (LFTs), creatinine, and plasma venous bicarbonate. ${ }^{83}$ The decision to stop NAC will then be based on these results taken in the context of clinical features such as right upper quadrant tenderness. ${ }^{83}$

Paracetamol concentrations obtained beyond 15 hours of non-staggered overdose must be interpreted with caution; the limit of detection of some laboratory assays may not be sufficient to distinguish between toxic and non-toxic paracetamol concentrations, and in addition a small error in the stated time of ingestion can have a significant impact on the interpretation of the plasma paracetamol concentration. ${ }^{103}$ In practice, clinical findings and laboratory markers indicating possible paracetamol toxicity are more useful in guiding management between 15 and 24 hours of paracetamol overdose. A paracetamol concentration either above or just below the line at any time beyond 15 hours of non-staggered ingestion is an indication for treatment with NAC. ${ }^{83} 88$

The plasma paracetamol concentration cannot be used to assess the risk of toxicity in patients presenting at more than 24 hours after ingestion. ${ }^{87}$ In this group the decision to treat is based on the presence of clinical features such as vomiting and right upper quadrant tenderness, the dose ingested (more than $150 \mathrm{mg} / \mathrm{kg}$ per 24 hours; $75 \mathrm{mg} / \mathrm{kg}$ per 24 hours in high risk groups), and the results of the INR, LFTs, creatinine, and plasma venous bicarbonate at presentation. $^{83}{ }^{86}$ If any of these are abnormal the patient should be treated with a full course of NAC..$^{83} 86$

\section{Staggered paracetamol poisoning}

The plasma paracetamol concentration cannot be used to assess the risk of toxicity in these patients and so the decision to administer NAC is based on amount ingested within a 24 hour period. ${ }^{87}$ Patients who have ingested greater than $150 \mathrm{mg} / \mathrm{kg}$ of paracetamol in any 24 hour period $(75 \mathrm{mg} / \mathrm{kg}$ if in a high risk group) are given the full course of NAC. ${ }^{83}$

Effective treatment of non-staggered paracetamol overdose is dependent on knowledge of time of ingestion while effective treatment of staggered overdose is dependent on knowledge of total amount ingested. In cases where there is doubt regarding one of these factors and toxicity is possible, it is safer to err on the side of caution and administer NAC.

NAC is associated with a $5 \%-15 \%$ incidence of anaphylactoid reactions. ${ }^{104} 105108$ These are dose dependent and commonly occur during the initial 15 minute infusion. ${ }^{105} 106$ Most reactions are short lived and are effectively managed by stopping the infusion for 30 minutes. ${ }^{106}$ Some patients may

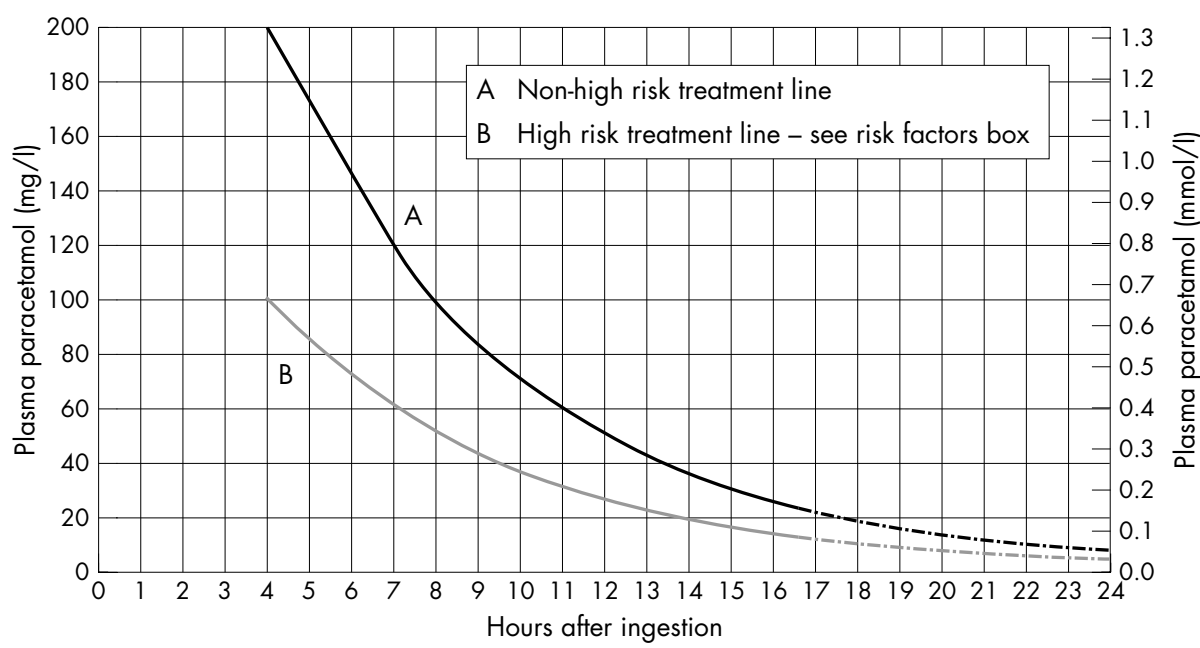

Figure 1 Prescolt nomogram for treatment of paracetamol poisoning. 
require an antihistamine. Reactions are more likely to occur in patients who have ingested smaller quantities of paracetamol and in asthmatic patients; however this is not a contraindication to the use of NAC in those where it is clinically indicated. ${ }^{107-109}$ Methionine is an oral antidote that can be used in patients with true anaphylaxis to NAC and in those where IV access cannot be obtained, however methionine has a number of disadvantages as an antidote and therefore its use should be discussed with a poisons centre. ${ }^{15}{ }^{110}$ Methionine is only effective in treating paracetamol toxicity if it is administered within 10 hours of paracetamol ingestion. ${ }^{110}$

Venous bicarbonate, LFTs, INR, and creatinine should be determined at the end of the course of NAC. If these are abnormal NAC is continued at $150 \mathrm{mg} / \mathrm{kg} / 24$ hours until the INR begins to improve. ${ }^{83} 111$ NAC directly decreases clotting factors and increases the measured INR slightly. ${ }^{112}$ An INR of up to 1.3 after a full course of NAC in conjunction with normal LFTs and creatinine in an asymptomatic well patient does not indicate hepatotoxicity and requires no further treatment. Any patient with one of the findings outlined in box 2 should be discussed with a specialist liver centre. ${ }^{113}$

Patients who have ingested any amount of paracetamol and exhibit no symptoms or signs other than vomiting, can safely be managed on a medical ward or ED observation ward. Patients with evidence of ALF should receive meticulous supportive care in an ICU environment and be discussed early with a specialist liver unit to ensure that transfer takes place before criteria for liver transplantation are met. ${ }^{114}$

\section{NSAIDS}

NSAIDs are ingested commonly in overdose, however severe toxicity is rare. ${ }^{115}$ Ibuprofen overdose was the second most common inquiry received by the NPIS (London) in 2002.

Ibuprofen ingestion of $>100 \mathrm{mg} / \mathrm{kg}$ is associated with GI symptoms including abdominal pain, vomiting, and diarrhoea. ${ }^{116}$ Seizures occur in up to $10 \%-20 \%$ of patients and are more common after mefenamic acid overdose. ${ }^{117}{ }^{118}$ Very large ingestions may cause drowsiness, coma, acidosis, apnoea, bradycardia, and renal failure. ${ }^{119-121}$ Patients who do not develop symptoms within four hours of ingestion are unlikely to experience delayed toxicity. ${ }^{115}$

Patients presenting within an hour of ingestion of $100 \mathrm{mg} /$ $\mathrm{kg}$ of ibuprofen or 10 tablets of any other NSAID should be given AC. $^{43}$ Seizures are often self limiting, but if persistent should be treated with benzodiazepines. ${ }^{15}$ Symptoms of gastrointestinal irritation are generally of short duration and therefore may be most effectively treated with antacids, a mucosal protective agent, or an oral proton pump inhibitor (PPI); there is currently little evidence showing which agent is most effective.

Box 2 Criteria for contacting a specialist liver centre after paracetamol overdose

- PT in seconds greater than the number of hours since ingestion

- INR $>2$ at 24 hours, $>4$ at 48 hours, greater than 6 at 72 hours

- Renal impairment (creatinine $>200 \mu \mathrm{mol} / \mathrm{I}$ )

- Hypoglycaemia

- Metabolic acidosis ( $\mathrm{pH}<7.35)$

- Hypotension despite fluid resuscitation

- Encephalopathy

\section{SALICYLATES}

Although salicylate poisoning is less common than it was 20 years ago, it remains the third most common inquiry received by both the London and Scottish NPIS. ${ }^{10}$ We have recently produced an evidence based flowchart to guide the management of salicylate poisoning. ${ }^{122}$ Table 3 summarises toxicokinetics, clinical features, and recommended management of salicylate poisoning.

Mild toxicity follows ingestion of more than $150 \mathrm{mg} / \mathrm{kg}$ of salicylate ${ }^{123} 124$ and is characterised by nausea, vomiting, tinnitus, and deafness. ${ }^{124}{ }^{125}$ Salicylates produce respiratory alkalosis secondary to direct stimulation of the respiratory centre. ${ }^{126}$ Uncoupling of oxidative phosphorylation produces metabolic acidosis, which increases the transit of salicylates into the CNS and decreases renal salicylate elimination. ${ }^{127}$ Children tend to present with a metabolic acidosis, whereas adults who present early after overdose commonly have a respiratory alkalosis that progresses to a mixed acid-base disturbance. ${ }^{128}$ Compensatory loss of electrolytes via the renal tract further complicates metabolic disturbances.

Moderate salicylate poisoning (ingestion of more than $250 \mathrm{mg} / \mathrm{kg}$ ) produces peripheral vasodilatation, sweating, and agitation. ${ }^{123}{ }^{124}$ Decreased platelet function can lead to petechiae and subconjunctival haemorrhage. Hypoglycaemia is more common in children. ${ }^{129}$ Severe salicylate poisoning follows ingestion of greater than $500 \mathrm{mg} / \mathrm{kg}^{123} 124$ and is characterised by metabolic acidosis, seizures, renal failure, agitation, coma, and eventually cardiovascular collapse. ${ }^{129}$ Pulmonary and cerebral oedema are rare.

Patients who have ingested more than $125 \mathrm{mg} / \mathrm{kg}$ of salicylate should be given AC. ${ }^{122}{ }^{130}$ Gastric lavage should be considered if patients present within one hour of ingestion of more than $500 \mathrm{mg} / \mathrm{kg} .{ }^{122}$ The use of MDAC is controversial in salicylate poisoning, but we currently recommend its use to prevent delayed absorption, until the plasma salicylate concentration has peaked..$^{42} 122131132$

Plasma salicylate concentration, FBC, and urea and electrolytes should be measured at least four hours after ingestion. ${ }^{122}$ However, the salicylate concentration at presentation can be an unreliable guide to the severity of poisoning, particularly after ingestion of enteric coated tablets, and levels may not peak until 12-18 hours after ingestion. We would therefore advise that the plasma salicylate concentration is repeated every three to four hours until the plasma concentration has peaked. ${ }^{122}$

Plasma salicylate concentrations correlate roughly with toxicity, however they need to be interpreted in the context of the clinical features and whether or not the patient has a metabolic acidosis. ${ }^{133}$ A metabolic acidosis is a particularly important negative predictor because it results in a decrease in renal elimination of salicylates, and an increase in the unionised salicylate concentration leading to increased transit into the CNS, higher CNS salicylate concentrations, and therefore greater CNS toxicity. ${ }^{122}$

Mild salicylate poisoning (salicylate concentration 300$600 \mathrm{mg} / \mathrm{l}$ in adults and $200-450 \mathrm{mg} / \mathrm{l}$ in children/elderly people ${ }^{133}{ }^{134}$ ) can be treated by rehydration using oral or IV fluids, and MDAC until the plasma salicylate concentration has peaked. ${ }^{122}$

Urinary alkalinisation is a simple and effective method of increasing renal excretion of salicylates ${ }^{57} 58135$ and should be used for patients with features of moderate salicylate poisoning (salicylate concentration $600-800 \mathrm{mg} / \mathrm{l}$ in adults and $450-700 \mathrm{mg} / \mathrm{l}$ in children/elderly people $\left.{ }^{133}{ }^{134}\right)$. Adults are given one litre of $1.26 \%$ sodium bicarbonate over three hours. ${ }^{122}$ Potassium $(20-40 \mathrm{mmol}$ ) is added to this solution to promote production of an alkaline urine and to combat potassium loss once an alkaline diuresis is achieved. Urine $\mathrm{pH}$ should be checked every 30 minutes with indicator paper to 


\begin{tabular}{|c|c|c|c|c|}
\hline Severity & Dose ingested & Salicylate concentration & Clinical features & $\begin{array}{l}\text { Recommended } \\
\text { management }\end{array}$ \\
\hline Mild & $>150 \mathrm{mg} / \mathrm{kg}$ & $\begin{array}{l}\text { Adults } 300-600 \mathrm{mg} / \mathrm{l} \\
\text { Children/elderly people 200- } \\
450 \mathrm{mg} / \mathrm{l}\end{array}$ & $\begin{array}{l}\text { Nausea } \\
\text { Vomiting } \\
\text { Tinnitus } \\
\text { Dizziness }\end{array}$ & $\begin{array}{l}\text { MDAC until } \\
\text { salicylate } \\
\text { concentration peaks } \\
\text { Oral or IV fluids }\end{array}$ \\
\hline Moderate & $>250 \mathrm{mg} / \mathrm{kg}$ & $\begin{array}{l}\text { Adults } 600-800 \mathrm{mg} / \mathrm{l} \\
\text { Children/elderly people } 450- \\
700 \mathrm{mg} / \mathrm{l}\end{array}$ & $\begin{array}{l}\text { Tachypnoea } \\
\text { Hyperpyrexia } \\
\text { Sweating } \\
\text { Dehydration } \\
\text { Ataxia }\end{array}$ & $\begin{array}{l}\text { MDAC } \\
\text { IV fluids } \\
\text { Urinary } \\
\text { alkalinisation }\end{array}$ \\
\hline Severe & $>500 \mathrm{mg} / \mathrm{kg}$ & $\begin{array}{l}\text { Adults }>800 \mathrm{mg} / \mathrm{l} \\
\text { Children/elderly people }> \\
700 \mathrm{mg} / \mathrm{l}\end{array}$ & $\begin{array}{l}\text { Hypotension } \\
\text { Metabolic acidosis } \\
\text { Renal failure } \\
\text { Coma } \\
\text { Convulsions }\end{array}$ & $\begin{array}{l}\text { MDAC } \\
\text { IV fluids } \\
\text { Haemodialysis }\end{array}$ \\
\hline
\end{tabular}

ensure a $\mathrm{pH}$ of $7.5-8.5$ is achieved; if there is difficulty in achieving adequate urinary alkalinsation (in the context of a normal serum potassium), a bolus of $8.4 \%$ sodium bicarbonate may be required as patients can have a significant base deficit. ${ }^{122}$

Patients with a significant metabolic acidosis $(\mathrm{pH}<7.3)$ should be treated with $50 \mathrm{ml} 8.4 \%$ sodium bicarbonate. ${ }^{15}$ Patients who have seizures, coma, acute renal failure, pulmonary oedema, or metabolic acidosis resistant to correction should receive haemodialysis; haemodialysis should also be considered in patients with a plasma salicylate concentration greater than $800 \mathrm{mg} / \mathrm{l}$ in adults or $700 \mathrm{mg} / \mathrm{l}$ in children or elderly patients. ${ }^{129} 136137$ Haemoperfusion is effective in decreasing salicylate concentrations, but does not correct acid-base disturbances and so haemodialysis is the extracorporeal method of choice in severe salicylate poisoning. ${ }^{122}$

\section{OPIOIDS}

Deliberate or recreational overdose of opioids including morphine, heroin, codeine, and methadone is a common ED presentation. Acute opioid poisoning causes about 300 deaths per year in the UK, most of these occur before hospital admission. $^{7}$

Provision of an adequate airway and ventilation, and the appropriate use of naloxone remain the most important aspects in treatment of acute opioid toxicity. ${ }^{24}$ Patients with significant opioid toxicity have pin-point pupils, depressed respiration, and a decreased level of consciousness. ${ }^{15}$ Mixed pharmacological effects arising from preparations containing an opioid and a stimulant drug (cocaine and heroin combined as a "speedball") may cloud this typical clinical picture.

Naloxone is an opioid antagonist. In life threatening acute opioid toxicity naloxone can be administered IM, IV, intranasally, or via an endotracheal tube. Ideally naloxone should be administered IV as this permits accurate titration of a dose to restore adequate respiratory function while avoiding complete arousal (which may produce an acute withdrawal state or an aggressive, uncooperative patient). ${ }^{138}$ Administration of naloxone via other routes can lead to unpredictable absorption and does not permit accurate dose titration. IM administration of naloxone does not guarantee opioid antagonism will continue for long enough to prevent further life threatening opioid toxicity after an aroused patient has left the ED, particularly in patients who have ingested long acting opioids such as methadone. ${ }^{139}$

The bolus dose of naloxone required in patients presenting with opioid poisoning can be difficult to predict and it is best to give small $(100 \mu \mathrm{g})$ boluses titrated against the level of consciousness (Glasgow coma score 13-14/15), respiratory rate/depth ( $R R>10-12)$, and oxygen saturations. We recommend that naloxone is titrated by mixing a known amount (typically $1200-2000 \mu \mathrm{g}$ ) in normal saline $(10 \mathrm{ml})$ and administering this slowly IV until the desired clinical state is achieved..$^{15}$ Naloxone can be safely used as a diagnostic tool in unconscious patients where opioid toxicity may be contributing to CNS depression. A total of $10 \mathrm{mg}$ of naloxone (given in increments) may be required to overcome opioid toxicity after a large overdose. ${ }^{138}$

Naloxone has a short half life (30-100 minutes) whereas some opioids (particularly oral agents such as methadone) have half lives of up to 24 hours. Therefore repeated doses of naloxone or an infusion are sometimes required. The dose of a naloxone infusion can be calculated by giving two thirds of the dose required to initially resuscitate the patient per hour. ${ }^{140}$ Patients who have ingested long acting opioids (such as methadone) or sustained release preparations (for example, MST continuous) may require naloxone infusions for up to 72 hours. Naloxone infusion rates required to overcome opioid toxicity may increase as blood opioid concentration rises after adsorption of sustained release preparations. Patients should be observed for at least four hours before discharge after stopping a naloxone infusion. ${ }^{15}$

Coproxamol is more likely to lead to death after overdose than other compound analgesics containing opioids. ${ }^{141}$ The opioid component, dextropropoxyphene has membrane stabilising effects and can produce QRS prolongation and negative cardiac inotropy. ${ }^{142}$ Cardiovascular compromise associated with QRS prolongation after coproxamol overdose may respond to IV sodium bicarbonate. ${ }^{143}$

All patients with opioid poisoning, particularly those who have ingested a compound opioid analgesic containing paracetamol, should have plasma paracetamol concentration measured. ${ }^{34}$ 


\section{BENZODIAZEPINES}

Benzodiazepine toxicity commonly produces drowsiness, and mid-sized or dilated pupils. Dysarthria, ataxia, nystagmus, agitation, and confusion can occur, however after lone benzodiazepine ingestion symptoms and signs are usually mild, well tolerated, and resolve within 24 hours. ${ }^{144}$ Large overdoses of benzodiazepines can produce mild hypotension and respiratory depression. Patients rarely develop a Glasgow coma score of less than 10 after lone benzodiazepine overdose. ${ }^{144}$

Benzodiazepine overdose is less well tolerated in patients who have ingested a significant quantity of another CNS depressant (including ethanol), those with chronic obstructive airway disease, and elderly patients. ${ }^{145} 146$

Activated charcoal may be considered in patients presenting within an hour of a very large benzodiazepine overdose. ${ }^{15}$ Lone benzodiazepine overdose is generally very well tolerated and the mainstay of treatment is supportive care. ${ }^{15}$

Flumazenil is a benzodiazepine antagonist acting on the GABA receptor. We do not advocate the use of flumazenil as either a diagnostic or therapeutic tool in the treatment of acute poisoning. Administration of flumazenil after a mixed overdose may unmask adverse effects of coingestants, particularly cardiotoxic agents such as TCAs leading to seizures or malignant arrhythmias. ${ }^{147-150}$ Patients who have a history of seizures may develop uncontrolled seizures after receiving flumazenil. ${ }^{151}$ Administration of flumazenil to patients with a history of long term benzodiazepine use can precipitate an acute withdrawal state. ${ }^{151}{ }^{152}$ It is much safer to provide supportive care until benzodiazepine toxicity has resolved. In rare circumstances where airway and ventilatory support are not available, lone benzodiazepine overdose is suspected, and the ingestion of any other drugs has been excluded, flumazenil may be used cautiously in small increments.

\section{TRICYCLIC ANTIDEPRESSANTS}

TCA overdose is the most common cause of acute poison related ICU admission in the UK. ${ }^{15}$ Ingestion of greater than $10 \mathrm{mg} / \mathrm{kg}$ of a TCA is likely to produce significant toxicity while $20-30 \mathrm{mg} / \mathrm{kg}$ is considered a potentially lethal dose. ${ }^{153}$

TCAs have a large number of pharmacological properties and therefore produce a wide range of clinical effects in overdose. Patients who have ingested a significant quantity of a TCA will generally exhibit clinical effects within one hour of ingestion. ${ }^{154}$ Severe clinical effects typically resolve over a 24-48 hour period. ${ }^{155}$ Patients who do not develop signs of toxicity for six hours hours after overdose can be safely discharged. ${ }^{15}$

The anticholinergic properties of TCAs produce sinus tachycardia, warm dry skin, brisk reflexes, sedation, seizures, and urinary retention. ${ }^{156}$ Pupils are commonly poorly reactive and dilated, but can vary in size. This cluster of signs helps to identify the causative agent in an unconscious patient who has ingested a TCA, but anticholinergic effects alone rarely cause death. Coma and ECG conduction abnormalities are more predictive of severe toxicity than anticholinergic signs alone. The high mortality rate (34.9 deaths per million prescriptions ${ }^{157}$ ) associated with TCAs is primarily caused by sodium channel block, which occurs in overdose and leads to cardiac conduction abnormalities. ${ }^{158}$ The $\alpha$ receptor block contributes to sedation and worsens systemic cardiovascular function by causing vasodilatation. ${ }^{156}$

Severe clinical effects after overdose include coma, seizures, malignant arrhythmias, and hypotension attributable to myocardial depression and peripheral vasodilatation. ${ }^{159} 160$ ECG abnormalities include QRS, QT, and PR prolongation, and right axis deviation. ${ }^{161}$ QRS duration is a prognostic factor and should be measured in all patients who have ingested a TCA in overdose. ${ }^{161}{ }^{162}$ QRS prolongation greater than $100 \mathrm{~ms}$ is associated with an increased risk of seizures while QRS prolongation greater than $160 \mathrm{~ms}$ increases the likelihood of malignant arrhythmias. ${ }^{162-164}$

Patients who have signs of severe toxicity should be sedated and receive meticulous supportive care in an ICU environment. ${ }^{15} 165$

Sodium bicarbonate is the first line agent used to treat TCA related cardiovascular toxicity. ${ }^{13}{ }^{161}$ Systemic alkalinisation and hypertonic sodium loading both contribute to sodium bicarbonate's mechanism of action in treating TCA related toxicity. ${ }^{158}{ }^{166-168}$

All patients with TCA poisoning who have cardiac arrhythmias, QRS prolongation of greater than $120 \mathrm{~ms}$, or hypotension should receive sodium bicarbonate even in the absence of acidosis. ${ }^{155} 156$ The initial dose of sodium bicarbonate is $1-2 \mathrm{ml} / \mathrm{kg}$ of an $8.4 \%$ IV solution given as a bolus and administered through a large peripheral vein if necessary, until central venous access is obtained. ${ }^{13}{ }^{167}$ Sodium bicarbonate boluses should be repeated until a pH of 7.50-7.55 is obtained. ${ }^{13}$ Patients with features of severe TCA toxicity (systolic $\mathrm{BP}<90 \mathrm{~mm} \mathrm{Hg}$, QRS duration of $>160 \mathrm{~ms}, \mathrm{pH}<7.1$, arrhythmias, recurrent seizures) may initially require large doses of sodium bicarbonate ( $1-3 \mathrm{ml} / \mathrm{kg}$ 8.4\% IV solution every three to five minutes titrated to clinical response to obtain a $\mathrm{pH}$ of 7.5-7.55). These patients should receive further bolus doses of IV $8.4 \%$ sodium bicarbonate or an IV infusion of $1.26 \%$ sodium bicarbonate to maintain a $\mathrm{pH}$ of 7.5-7.55. Administration of sodium bicarbonate can cause hypokalaemia and so it is important that the serum potassium is monitored and potassium supplementation given as necessary. ${ }^{13}$

Patients who remain hypotensive despite a $\mathrm{pH}$ in the range of 7.50-7.55 and adequate central venous filling should be discussed with a clinical toxicologist. They may require additional hypertonic saline and the cautious use of inotropes such as adrenaline and norepinephrine (noradrenaline) to maintain adequate systemic perfusion. ${ }^{156}{ }^{165}$ Adrenaline and norepinephrine have the potential to cause further cardiac toxicity and should only be used after administration of sodium bicarbonate.

All antiarrhythmics should be avoided where possible in patients with TCA poisoning, particularly class Ia antiarrhythmics (quinidine, procainamide, and disopyramide), which are contraindicated in the treatment of TCA induced cardiac arrhythmias. ${ }^{156}$ Atrioventricular block resistant to treatment with sodium bicarbonate may require temporary cardiac pacing. Prolonged (one hour) resuscitation after TCA induced cardiac arrest has been associated with full neurological recovery ${ }^{169} 170$; hypertonic sodium bicarbonate should be used early in the resuscitation of these patients. ${ }^{13}$ Ventricular tachyarrhythmias resistant to treatment with sodium bicarbonate (with pH 7.50-7.55) are best treated with either DC cardioversion or overdrive pacing. ${ }^{15}$

Seizures are generally short lived and are treated using benzodiazepines. ${ }^{171}$ Patients who have seizures should receive sodium bicarbonate (1-2 ml/kg bolus of $8.4 \%$ IV solution, repeated every 15-30 minutes to maintain $\mathrm{pH} 7.5-7.55)$ to limit further acidosis (which increases the risk of arrhythmias) and the transit of TCA into the CNS. ${ }^{166}$ Resistant seizures should be treated aggressively with general anaesthetic sedation and supportive care. ${ }^{15}$

\section{SELECTIVE SEROTONIN REUPTAKE INHIBITORS}

SSRIs taken in overdose commonly produce drowsiness and sinus tachycardia, however ingestions of less than $500 \mathrm{mg}$ rarely cause clinically significant toxicity. ${ }^{172}$ Nausea, vomiting, diarrhoea, and dizziness can occur. Serious clinical 
effects (hypotension, coma, seizures) may occur with ingestions of greater than $1500 \mathrm{mg} .{ }^{173-175}$

Citalopram causes QRS and QT prolongation. ${ }^{176}$ Venlafaxine, a selective norepinephrine (noradrenaline) reuptake inhibitor is associated with seizures ${ }^{177}{ }^{178}$ and causes QRS prolongation. ${ }^{179-181}$

AC is indicated within one hour of ingestion of more than 10 tablets of an SSRI. Patients should be observed for six hours and symptomatic patients should be cardiac monitored. Venlafaxine is available in a modified release preparation and so prolonged clinical toxicity may be observed after overdose. ${ }^{16}$ Convulsions can be treated with benzodiazepines. $^{15}$

The combination of SSRIs with other agents such as, dextromorphan, MDMA, lithium, TCAs, and monoamine oxidase inhibitors that also increase CNS serotonin concentrations may lead to the development of the serotonin syndrome. ${ }^{182}$ The serotonin syndrome can also occur after lone SSRI overdose, or overdose of SSRIs and non-serotonergic agents. ${ }^{183}$ This is characterised by changed mental status (agitation, confusion, coma), autonomic instability (diaphoresis, hyperpyrexia, tachycardia, hypertension), and neuromuscular dysfunction (myoclonus, hyper-reflexia, muscle rigidity, tremor) ${ }^{184}$ and can potentially occur with therapeutic doses of serotonergic agents. ${ }^{185} 186$ Effective management includes good supportive, care and the withdrawal of all serotonergic agents. ${ }^{15}{ }^{187}$ Benzodiazepines should be used to treat agitated patients and should also be used in combination with cooling measures to treat hyperthermic patients. ${ }^{15}$ Patients with severe features of toxicity or those not responding to supportive care should be discussed with a clinical toxicologist. They may benefit from administration of serotonin antagonists such as cyproheptadine. ${ }^{188}$

\section{COCAINE RELATED ACUTE CORONARY SYNDROME}

Cocaine related chest pain might be musculoskeletal, respiratory, or cardiac in origin. Cocaine related myocardial infarction (MI) occurs in $6 \%$ of patients with cocaine related chest pain. ${ }^{189}$ It is unrelated to the dose ingested and route of administration. ${ }^{190}$ It has been reported to occur in first time as well as habitual users. ${ }^{190}$ The risk of acute coronary syndrome (ACS) is increased by a factor of 24 in the first hour after cocaine use but may be delayed for four to six hours. ${ }^{191}$

Cocaine related ACS is caused by a number of mechanisms. The sympathomimetic action of cocaine produces an increase in myocardial oxygen demand by increasing heart rate and myocardial contractility. In the face of increased myocardial oxygen demand, supply is limited by direct cocaine induced coronary artery vasospasm, ${ }^{192}$ an effect more pronounced in diseased vessels ${ }^{193}$ and smokers. ${ }^{194}$ Cocaine increases platelet activation and aggregation, ${ }^{195-197}$ and can produce vascular endothelial damage and accelerated atherosclerosis in long term users. ${ }^{198-200}$

Diagnosis of cocaine related MI is difficult as $84 \%$ of patients with cocaine related chest pain have abnormal ECGs even in the absence of MI. ${ }^{189}{ }^{201}$ Half of all cocaine users have increased creatinine kinase concentrations in the absence of MI. ${ }^{201} 202$ Troponin concentrations are more sensitive and specific in diagnosing MI. ${ }^{190}$

The management of cocaine related ACS differs from that of classic "medical ACS" because of cocaine induced coronary artery spasm that is present in addition to possible coronary artery thrombosis (secondary to coagulation abnormalities and advanced atheromatous disease). ${ }^{189} \beta$ Blockers are contraindicated in the treatment of cocaine related ACS. ${ }^{203}$ $\beta$ Receptor block produces unopposed $\alpha$ receptor stimulation and worsening of coronary artery spasm and systemic hypertension. Thrombolysis should not be used routinely as this will not overcome coronary artery spasm and can increase the risk of intracranial haemorrhage associated with hypertension secondary to cocaine use. ${ }^{190}$

First line agents used in the treatment of cocaine related ACS are oxygen, benzodiazepines (which reduce central stimulation, tachycardia, and hypertension), IV or buccal nitrates (to overcome coronary artery vasospasm), and aspirin (to reduce platelet aggregation). ${ }^{204} 205$ Second line agents include calcium channel blockers (verapamil) and $\alpha$ blockers such as phentolamine. ${ }^{204} 205$ Patients with continuing chest pain and/or ECG changes despite these measures should undergo coronary angiography. ${ }^{190}$

If coronary artery angiography shows vascular spasm, GTN can be injected directly into the vascular lumen. Thombolytic reperfusion therapy can lead to a clinically significant haemorrhage and should only be given if angiography shows a thrombosis or medical treatment fails and angiography is not available. ${ }^{190}$

\section{PSYCHOLOGICAL ASSESSMENT}

All patients who present after deliberate self poisoning should be assessed to determine the risk of further self harm. Box 3 lists the risk factors indicating serious self harm intent and high likelihood of further significant self harm. ${ }^{1}$ Patients who are at risk of further self harm should receive appropriate assessment by the psychiatry team during medical treatment of the poisoning.

Patients who are not at risk of further self harm can complete medical treatment before undergoing a psychological assessment before discharge. The use of antidepressants with low toxicity in overdose (SSRIs) should be considered in depressed patients who require pharmacological treatment. ${ }^{15} 181$

\section{CONCLUSIONS}

Most acutely poisoned patients can be managed with supportive care during a period of observation in an ED observation ward or general medical ward, or for those with severe poisoning, a critical care ward (HDU or ICU). Information sources are available to identify patients who will benefit form an early or specific intervention. The potential benefit of using gastrointestinal decontamination techniques and methods to increase toxin elimination should be assessed for each individual patient.

The commonest form of self poisoning in the UK is paracetamol poisoning. Presentation within eight hours of ingestion can be successfully treated with the antidote $N$ acetylcysteine, but delay in antidote administration beyond eight hours is associated with reduced efficacy and increased risk of hepatotoxicity. In cases where the time of ingestion or amount of paracetamol ingested is unclear it is safest to treat

Box 3 Factors indicating serious self harm intent and high likelihood of further significant self harm

- Sex (male)

- Age (elderly)

- Recently bereaved

- Unemployed

- Suicide note

- Evidence of planning of overdose

- Presence of terminal illness

- History of depression

- Found in isolated place by another person after taking overdose 
the patient with NAC. Patients with signs of ALF should receive further NAC and be discussed with a specialist liver unit.

The reduction in the price of drugs of misuse has lead to an increase in opioid, cocaine, and benzodiazepine poisoning. Naloxone is a safe antidote that can be used as a diagnostic and therapeutic agent in treating opioid poisoning. Naloxone is best administered IV and titrated to restore adequate respiratory function. Flumazenil should not routinely be used to treat benzodiazepine poisoning because of the risk of significant adverse events; most patients are successfully treated with good supportive care. Thrombolysis is not routinely indicated in the treatment of patients with cocaine related myocardial infarction. Initial treatment is aimed at decreasing coronary artery spasm (with benzodiazepines and nitrates) and platelet aggregation (with aspirin)

TCAs are more toxic in overdose relative to SSRIs. Sodium bicarbonate is the antidote of choice in TCA poisoning and should be used early in patients who have QRS prolongation, cardiac arrhythmias, hypotension, or seizures. QRS prolongation is a prognostic indicator for the occurrence of seizures and malignant arrhythmias.

All poisoned patients who have taken an intentional overdose should undergo a psychological assessment as a routine part of their treatment.

\section{Authors' affiliations}

S L Greene, P I Dargan, A L Jones, National Poisons Information Service (London), Guy's and St Thomas's NHS Trust, UK

Funding: none.

Conflicts of interest: none declared.

\section{REFERENCES}

1 Townsend E, Hawton K, Harriss L, et al. Substances used in deliberate selfpoisoning 1985-1997: trends and associations with age, gender, repetition and suicide intent. Soc Psychiatry Psychiatr Epidemiol 2001;36:228-34.

2 WHO/EURO. Results of the WHO/EURO multicentre study on parasuicide. Acta Psychiatr Scand 1996:93:327-38

3 Michel K, Ballinari P, Bille-Brahe U, et al. Methods used for parasuicide: results of the WHO/EURO Multicentre Study on Parasuicide. Soc Psychiatry Psychiatr Epidemiol 2000;35:156-63.

4 Schmidtke A, Bille-Brahe U, Deleo D, et al. Attempted suicide in Europe: rates, trends, and sociodemographic characteristics of suicide attempters during the period 1989-1992. Acta Psychiatr Scand 1996;93:327-38.

5 Gunnell D, Ho D, Murray V. Medical management of deliberate drug overdose: a neglected area for suicide prevention? Emerg Med J 2004;21:35-8.

6 Watson WA, Litovitz TL, Rodgers GC, et al. 2002 Annual report of the American Association of Poison Control Centres Toxic Exposure Surveillance System. Am J Emerg Med 2003;21:353-421.

7 Flanagan RJ, Rooney C. Recording acute poisoning deaths. Forensic Sci Int 2002; 128:3-19.

8 Hawton K, Fagg J, Simkin S, et al. Trends in deliberate self-harm in Oxford, 1985-1995. Implications for clinical services and the prevention of suicide. Br J Psychiatry 1997;171:556-60.

9 Hawton K, Townsend E, Deeks J, et al. Effects of legislation restricting pack sizes of paracetamol and salicylate on self poisoning in the United Kingdom: before and after study. BMJ 2001:322:1203-7.

10 Camidge DR, Wood RJ, Bateman DN. The epidemiology of self-poisoning in the UK. Br J Clin Pharmacol 2003;56:613-19.

11 Flanagan RJ, Jones AL. Antidotes. London: Taylor-Francis, 2001

12 Okumura T, Suzuki K, Fukuda A, et al. The Tokyo subway Sarin attack disaster management. Part 2; Hospital report. Acad Emerg Med 1998;6:618-24

13 Albertson TE, Dawson A, de Latorre F, et al. American Heart Association; International Liaison Committee on Resuscitation. TOX-ACLS: toxicologic-oriented advanced cardiac life support, Ann Emerg Med 2001;37:S78-90.

14 Mokhlesi B, Leikin JB, Murray P, et al. Adult toxicology in critical care: Part II: specific poisonings. Chest, 2003 Mar, 123:897-922.

15 Jones AL, Dargan PI. Churchill's pocket book of toxicology. London: Churchill Livingstone, 2001

16 British Medical Association, Royal Pharmaceutical Society of Great Britain British National Formulary. London: BMA/RPSGB, Mar, 2004.

17 Callaham M, Schumaker H, Pentel P. Phenytoin prophylaxis of cardiotoxicity in experimental amitriptyline poisoning. J Pharmacol Exp Ther 1988;245:216-20
18 Markowitz JC, Brown RP. Seizures with neuroleptics and antidepressants. Gen Hosp Psychiatry 1987;9:135-41.

19 Wech R, Chue P. Antipsychotic agents and QT changes. J Psychiatry Neurosci 2000;25:154-60

20 Blum K, Eubanks JD, Wallace JE, et al. Enhancement of alcohol withdrawal convulsions in mice by haloperidol. Clin Toxicol 1976;9:427-34.

21 Derlet RW, Albertson TE, Rice P. The effect of haloperidol in cocaine and amphetamine intoxication. J Emerg Med 1989;7:633-7.

22 Bosse GM. Antidiabetic and Hypoglycaemic Agents. In: Goldfrank LR Flomenbaum NE, Lewin NA, et al. Goldfranks toxicologic emergencies. 7th ed. New York: McGraw-Hill, 2002:858-9.

23 Graudins A, Linden CH, Ferm RP. Diagnosis and treatment of sulfonylureainduced hyperinsulinemic hypoglycemia. Am J Emerg Med 1997;15:95-6.

24 Clarke SF, Dargan PI, Jones AL. Naloxone-a systematic review. Emerg Med J (in press).

25 Hoffman RS, Goldfrank LR. The poisoned patient with altered consciousness Controversies in the use of a 'coma cocktail'. JAMA 1995;274:562-9.

26 Schrier RW, Henderson HS, Tisher CC, et al. Nephropathy associated with heat stress and exercise. Ann Intern Med 1967;67:356-76.

27 Vertel RM, Knochel JP. Acute renal failure due to heat injury. An analysis of en cases associated with a high incidence of myoglobinuria. Am J Med 1967:43:435-51.

28 Greene SL, Dargan PI, O'Connor N, et al. Multiple toxicity from 3,4methylenedioxymethamphetamine ("ecstasy"). Am J Emerg Med 2003;21:121-4

29 Ginsberg MD, Hertzman M, Schmidt-Nowara WW. Amphetamine intoxication with coagulopathy, hyperthermia, and reversible renal failure. A syndrome resembling heatstroke. Ann Intern Med 1970;73:81-5.

30 Hollander JE, Hoffman RS. Cocaine. In: Goldfrank LR, Flomenbaum NE, Lewin NA, et al. Goldfranks toxicologic emergencies. 7th ed. New York: McGraw-Hill, 2002:1004-17.

31 Graudins A, Stearman A, Chan B. Treatment of the serotonin syndrome with cyproheptadine. J Emerg Med 1998;16:615-19.

32 Mc Caron MM, Boettger ML, Peck JJ. A case of neuroleptic malignant syndrome successfully treated with amantadine. J Clin Psychiatry 1982;43:381-2

33 Greene SL, Dargan PI, Shin GY, et al. Doctors and nurses estimation of the weight of patients - a source of systematic error? J Toxicol Clin Toxicol 2004:42:611-15.

34 Dargan PI, Ladhani S, Jones AL. Measuring plasma paracetamol concentrations in all patients with drug overdose or altered consciousness: does it change outcome? Emerg Med J 2001;18:178-82.

35 Hartington K, Hartley J, Clancy M. Measuring plasma paracetamo concentrations in all patients with drug overdoses; development of a clinical decision rule and clinicians willingness to use it. Emerg Med J 2002;19:408-11.

36 Wood DM, Dargan PI, Jones AL. Measuringplasma salicylate concentrations in all patients with drug overdose or altered consciousness: is it necessary? Emerg Med J (in press).

37 Rainley PM. Laboratory principles and techniques for evaluation of the poisoned or overdosed pateint. In: Goldfrank LR, Flomenbaum NE, Lewin NA, et al. Goldfranks toxicologic emergencies. 7th ed. New York: McGraw-Hill, 2002:69-93.

38 Baselt RC. Disposition of toxic drugs and chemicals in man, 6th ed. Foster City, CA: Biomedical Publications, 2002:247-53.

39 National Poisons Information Service; Association of Clinical Biochemists. Laboratory analyses for poisoned patients: joint position paper. Ann Clin Biochem 2002;39:328-39.

40 Wu AH, McKay C, Broussard LA, et al. National academy of clinical biochemistry laboratory medicine practice guidelines: recommendations for the use of laboratory tests to support poisoned patients who present to the emergency department. Clin Chem 2003;49:357-79.

41 Dawson AH, Whyte IM. Evidence in clinical toxicology: the role of therapeutic drug monitoring. Ther Drug Monit 2002;24:159-62.

42 Baselt RC. Disposition of toxic drugs and chemicals in man. 6th ed. Foster City, CA: Biomedical Publications, 2002:472-5, 707-10.

43 American Academy of Clinical Toxicology and European Association of Poisons Control Centres and Clinical Toxicologists. Position statement: Single-dose activated charcoal. J Toxicol Clin Toxicol 1997:35:721-41.

44 American Academy of Clinical Toxicology and European Association of Poisons Control Centres and Clinical Toxicologists. Position statement: ipecac syrup. J Toxicol Clin Toxicol 1997;35:699-709.

45 American Academy of Clinical Toxicology; European Association of Poisons Centres and Clinical Toxicologists. Position statement and practice guidelines on the use of multi-dose activated charcoal in the treatment of acute poisoning. J Toxicol Clin Toxicol 1999;37:731-51.

46 American Academy of Clinical Toxicology and European Association of Poisons Control Centres and Clinical Toxicologists. Position statement: gastric lavage. J Toxicol Clin Toxicol 1997;35:711-19.

47 American Academy of Clinical Toxicology and European Association of Poison Control Centres and Clinical Toxicologists. Position statement: whole bowel irrigation. J Toxicol Clin Toxicol 1997;35:753-62.

48 Thakore S, Murphy N. The potential role of prehospital administration of activated charcoal. Emerg Med J 2002;19:63-5.

49 Karim A, lvatts S, Dargan PI, et al. How feasible is it to conform to the European guidelines on the administration of activated charcoal within one hour of overdose? Emerg Med J 2001;18:390-2.

50 Wolseley BA, McKinney PE. Does transportation by ambulance decrease time to gastrointestinal decontamination after overdose? Ann Emerg Med 2000;35:579-84. 
51 Bond GR. The role of activated charcoal and gastric emptying in gastrointestinal decontamination: a state-of-the-art review. Ann Emerg Med, 2002 Mar, 39:273-86

52 Neuvonen PJ, Olkkola KT. Oral activated charcoal in the treatment of intoxications. Role of single and repeated doses. Med Toxicol Adverse Drug Exp 1988;3:33-58.

53 Saetta JP, March S, Gaunt ME. Gastric emptying procedures in the self poisoned patient: are we forcing gastric content beyond the pylorus? J $R$ Soc Med 1991;84:274-6.

54 Eddleston M, Juszczak E, Buckley N. Does gastric lavage really push poisons beyond the pylorus? A systematic review of the evidence. Ann Emerg Med 2003;42:359-64.

55 Thompson AM, Robins JB, Prescott LF. Changes in cardiorespiratory function during gastric lavage for drug overdose. Hum Exp Toxicol 1987;6:215-18.

56 Tenenbein $M$. Whole bowel irrigation as a gastrointestinal decontamination procedure after acute poisoning. Med Toxicol 1988;3:77-84.

57 Morgan AG, Polak A. The excretion of salicylate in salicylate poisoning. Clin Sci 1971:41:475-84.

58 Proudfoot AT, Krenzelok EP, Vale JA. Position Paper on urine alkalinization J Toxicol Clin Toxicol 2004;42: 1-26.

59 Pond SM. Diuresis, dialysis, and hemoperfusion. Indications and benefits. Emerg Med Clin North Am 1984;2:29-45.

60 Scharman EJ. Methods used to decrease lithium absorption or enhance elimination. J Toxicol Clin Toxicol 1997;35:601-8.

61 Jacobsen D, Wilk-Larsen E, Bredesen JE. Haemodialysis or haemoperfusion in severe salicylate poisoning? Hum Toxicol 1988;7:161-3

62 Hootkins R Sr, Lerman MJ, Thompson JR. Sequential and simultaneous "in series" hemodialysis and hemoperfusion in the management of theophylline intoxication. J Am Soc Nephrol 1990;1:923-6.

63 Barceloux DG Bond GR, Krenzelok EP, et al. American Academy of Clinical Toxicology Ad Hoc Committee on the Treatment Guidelines for Methanol Poisoning. J Toxicol Clin Toxicol 2002;40:415-46.

64 Barceloux DG, Krenzelok EP, Olsen K, et al. American Academy of Clinical Toxicology Practice guidelines on the treatment of ethylene glycol poisoning. Ad Hoc Committee. J Toxicol Clin Toxicol 1999;37:537-60.

65 Park GD, Spector R, Roberts RJ, et al. Use of hemoperfusion for treatment of theophylline intoxication. Am J Med 1983;74:961-6.

66 Cutler RD, Forland SC, John PG. Extracorporeal removal of drugs and poisons by hemodialysis and hemoperfusion. Ann Rev Pharmacol Toxicol 1987;27:169-91.

67 Bar-Oz B, Levichek Z, Koren G. Medications that can be fatal for a toddler with one tablet or teaspoonful: a 2004 update. Pediatric Drugs 2004;6:123-6.

68 Koren G. Medications which can kill a toddler with one tablet or teaspoon. J Toxicol Clin Toxicol 1993;31:407-13

69 Liebelt EL, Shannon MW. Small doses, big problems: a selected review of highly toxic common medications. Pediatr Emerg Care 1993;9:292-7.

70 Anderson BJ, Holford NHG, Armishaw JC. Predicting concentrations in children presenting with acetaminophen overdose. J Pediatr 1999; 135:290-5.

71 Bond GR, Krenzelok EP, Normann SA. Acetaminophen ingestion in childhood-cost and relative risk of alternative referral strategies. J Toxico Clin Toxicol 1994;32:513-25.

72 Mohler CR, Nordt SP, Williams SR, et al. Prospective evaluation of mild to moderate pediatric acetaminophen exposures. Ann Emerg Med 2000;35:239-44.

73 Caravati EM. Unintentional acetaminophen ingestion in children and the potential for hepatotoxicity. J Toxicol Clin Toxicol 2000;38:291-6.

74 Litovitz T, Schmitz BF. Ingestionn of cylindrical and button batteries: an analysis of 2382 cases. J Pediatr 1984;89:747-57.

75 Kulig K, Rumack C, Rumack B, et al. Disk battery ingestion-elevated urine mercury levels and enema removal of battery fragments. JAMA 1983;249:2502-4

76 Singalet $D$, Lees $G$. Tracheosophageal injury secondary to disk battery ingestion. J Pediatr Surg 1988;23:996-8.

77 Wilson JA, Phillips EM. Endoscopic retrieval of a miniature battery. Gut 1985;26:215

78 Rumack Cm, Rumack BH. Battery Ingestions. Pediatrics 1992;89:771-2

79 Liovitz T, Butterfield AB, Holloway RR, et al. Battery ingestion: assessment of therapeutic modalities and battery discharge state. J Pediatr 1984; 105:868-73.

80 Litovitz TL, Flagler SL, Manoguerra AS, et al. Recurrent poisonings among pediatric poisoning victims. Med Toxicol 1989:4:381-6.

81 Demorest RA, Posner JC, Osterhoudt KC, et al. Poisoning prevention education during emergency department visits for childhood poisoning. Pediatr Emerg Care 2004;20:281-4.

82 Fagan E, Wannan G. Reducing paracetamol overdoses. BM 1996:313:1417-18

83 Wallace Cl, Dargan PI, Jones AL. Paracetamol overdose: an evidence based flowchart to guide management. Emerg Med J 2002;19:202-5.

84 Prescott LF, Illingworth RN, Critchley JA, et al. Intravenous N-acetylcysteine: the treatment of choice for paracetamol poisoning. BMJ 1979:2:1097-100.

85 Jones AL. Recent advances in the management of late paracetamol poisoning. Emergency Medicine (Australia) 2000;12:14-21.

86 Jones AL. Mechanism of action and value of $\mathrm{N}$-acetylcysteine in the treatment of early and late acetaminophen poisoning: a critical review. J Toxicol Clin Tox 1998;36:277-85.

87 Prescott LF. Paracetamol overdosage: pharmacological considerations and clinical management. Drugs 1983;23:290-314
88 NPIS. Management of acute paracetamol poisoning, Guidelines agreed by the UK National Poisons Information Service 1998. (Supplied to Accident and Emergency Centres in the United Kingdom by the Paracetamol Information Centre in collaboration with the British Association for Accident and Emergency Medicine). London: NPIS, 1998.

89 Prescott LF. Paracetamol (acetaminophen). A critical bibliographic review. London: Taylor and Francis, 1996.

90 Buhl R, Jaffe HA, Holroyd KA. Systemic glutathione deficiency in symptomfree HIV-seropositive individuals. Lancet 1989;ii: 1294-8.

91 Whitcomb DC, Block GD. Association of acetaminophen hepatotoxicity with fasting and ethanol use. JAMA 1994;272:1845-50.

92 Wright N, Prescott LF. Potentiation by previous drug therapy of hepatotoxicity following paracetamol overdose. Scott Med J 1973;18:56-8.

93 Smith JA, Hine ID, Beck P, et al. Paracetamol toxicity: is enzyme induction important? Hum Exp Toxicol 1986;5:383-5.

94 Minton N, Henry JA, Frankel RJ. Fatal paracetamol poisoning in an epileptic. Hum Exp Toxicol 1988;7:33-4.

95 Prescott LF. Paracetamol, alcohol and the liver. Br J Clin Pharmacol 2000:49:291-301.

96 Bray GP, Mowat C, Muir DF, et al. The effect of chronic alcohol intake on prognosis and outcome in paracetamol overdose. Hum Exp Toxicol 1991; 10:435-8.

97 Buckley NA, Sinivasan J. Should a lower treatment line be used when treating paracetamol poisoning in patients with chronic alcoholism? : a case for, Drug Saf 2002;25:619-24.

98 Dargan PI, Jones AL. Should a lower treatment line be used when treating paracetamol poisoning in patients with chronic alcoholism? : a case against, Drug Saf 2002;25:625-32

99 Buckley NA, Whyte IM, O'Connell DL, et al. Activated charcoal reduces the need for $\mathrm{N}$-acetylcysteine treatment after acetaminophen (paracetamol) overdose. J Toxicol Clin Toxicol 1999;37:753-7.

100 Clark RF, Chen R, Williams SR, et al. The use of ondansetron in the treatment of nausea and vomiting associated with acetaminophen poisoning. J Toxicol Clin Toxicol 1996;34:163-7.

101 Prescott LF, Park J, Ballantyne A, et al. Treatment of paracetamol (acetaminophen) poisoning with $\mathrm{N}$-acetylcysteine. Lancet 1977;ii:432-4.

102 Prescott LF, Roscoe P, Wright N, et al. Plasma-paracetamol half-life and hepatic necrosis in patients with paracetamol overdosage. Lancet 1971;i:519-22.

103 Vale JA, Proudfoot AT. Paracetamol (acetaminophen) poisoning. Lance 1995; 346:547-52

104 Mant TG, Tempowski JH, Volans GN, et al. Adverse reactions to acetylcysteine and effects of overdose. BMJ 1984;289:217-19.

105 Buckley NA, Whyte IM, O'Connell DL, et al. Activated charcoal reduces the need for $\mathrm{N}$-acetylcysteine treatment after acetaminophen (paracetamol) overdose. J Toxicol Clin Toxicol 1999:37:753-7.

106 Bailey B, McGuigan MA. Management of anaphylactoid reactions to Nacetylcysteine. Ann Emerg Med 1998;31:710-15

107 Ho SW, Beilin ப. Asthma associated with N-acetylcysteine infusion and paracetamol poisoning:report of two cases. BMJ (Clin Res Ed) 1983;287:876-7.

108 Schmidt LE, Dalhoff K. Risk factors in the development of adverse reactions to $\mathrm{N}$-acetylcysteine in patients with paracetamol poisoning. Br J Clin Pharmacol 2001;51:87-91.

109 Appelboam AV, Dargan PI, Knighton J. Fatal anaphylactoid reaction to Nacetylcysteine: caution in patients with asthma. Emerg Med J 2002; 19:594-5.

110 Vale JA, Meredith TJ, Goulding R. Treatment of acetaminophen poisoning The use of oral methionine. Arch Intern Med 1981;141:394-6.

111 Harrison PM, Keays R, Bray GP, et al. Improved outcome of paracetamo induced fulminant hepatic failure by late administration of acetylcysteine. Lancet 1990;335: 1572-3

112 Whyte IM, Seldon M, Buckley NA, et al. Effect of paracetamol poisoning on international normalised ratio. Lancet 2003;361:429.

113 Makin A, Williams R. The current management of paracetamol overdosage. Br J Clin Pharmacol 1994;48:144-8.

114 Dargan PI, Jones AL. Acetaminophen poisoning: an update for the intensivist. Crit Care 2002;6:108-10.

115 Hall AH, Smolinskie SC, Conrad FL. Ibuprofen overdose: 126 cases. Ann Emerg Med 1986:15:1308-12.

116 Halpern SM, Fitzpatrick R, Volans GN. Ibuprofen toxicity: a review of adverse reactions and overdose. Adverse Drug React Toxicol Rev 1993; 12:107-28

117 Hall AH, Smolinske SC, Kulig KW. Ibuprofen overdose: a prospective study. West J Med 1988;48:653-6.

118 Balai-Mood M, Proudfoot AT, Critchley J. Mefanamic acid overdose. Lancet 1981 ;ii:1324-56.

119 Linden CH, Townswend PL. Metabolic acidosis after acute ibuprofen overdose. J Pediatr 1987;111:922-5.

120 Kulling PE, Backman EA, Skagius AS. Renal Impairment after acute diclofenac, naproxen, and sulindac overdoses. Clin Toxicol J Toxicol 1995;33:173-7.

121 Kertesz A. Neurological complications of non-steroidal anti-inflammatory agents. In: Borda I, Koff R, eds. Nonsteroidal Antiinflammatory drugs: a profile of adverse effects. Philadelphia: Hanley and Belfus, 1992: 147-55

122 Dargan PI, Wallace Cl, Jones AL. An evidence based flowchart to guide the management of acute salicylate (aspirin) overdose. Emerg Med J 2002;19:206-9.

123 Brenner BE, Simon RR. Mangement of salicylate intoxication. Drugs 1982;24:335-40. 
124 Temple AR. Acute and chronic effects of aspirin toxicity and their treatment Arch Intern Med 1981;141:364-9.

125 Gabow PA. How to avoid overlooking salicylate intoxication. J Crit Illness 1986;1:77-85

126 Tenney SM, Miller RM. The respiratory and circulatory action of salicylate. Am J Med 1955; 19:498-508.

127 Kaplan E, Kennedy J, David J. Effects of salicylates and other bezoates on oxidative enzymes of the tricarboxylic cycle in rat tissue homogenates. Arch Biochem Biophys 1954;51:47-61.

128 Gaudreault $\mathrm{P}$, Temple AR, Lovejoy FH Jr. The relative severity of acute versus chronic salicylate poisoning in children: a clinical comparison. Pediatrics 1982;70:566-9.

129 Chapman BJ, Proudfoot AT. Adult salicylate poisoning: deaths and outcome in patients with high plasma salicylate concentrations. $Q J$ Med 1989;72:699-707.

130 Danel V, Henry JA, Glucksman E. Activated charcoal, emesis, and gastric lavage in aspirin overdose. BMJ (Clin Res Ed) 1988;296:1507.

131 Hillman RJ, Prescott LF. Treatment of salicylate poisoning with repeated oral charcoal. BMJ (Clin Res Ed) 1985;291:1472.

132 Kirshenbaum LA, Mathews SC, Sitar DS, et al. Does multiple-dose charcoal therapy enhance salicylate excretion? Arch Intern Med 1990;150:1281-3.

133 Proudfoot AT. Toxicity of salicylates. Am J Med 1983;75:99-103.

134 Done AK. Salicylate intoxication: significance of measurements of salicylate in blood in cases of acute intoxication. Pediatrics 1960;26:800-7.

135 Prescott LF, Balali-Mood M, Critchley JA, et al. Diuresis or urinary alkalinisation for salicylate poisoning? BMJ (Clin Res Ed) 1982;285: 1383-6.

136 Yip L, Dart RC, Gabow PA. Concepts and controversies in salicylate toxicity Emerg Med Clin North Am 1994; 12:351-64.

137 Todd PJ, Sills JA, Harris F, et al. Problems with overdoses of sustainedrelease aspirin. Lancet $1981 ; i: 777$.

138 Nelson LS. Opioids. In: Goldfrank LR, Flomenbaum NE, Lewin NA, et al. Goldfranks toxicologic emergencies. 7th ed. New York: McGraw-Hill, 2002:901-23.

139 Watson WA. Opioid toxicity recurrence after an initial response to naloxone. Clin Toxicol 1998;36:1 1-17.

140 Goldfrank L, Weisman RS, Errick JK, et al. A dosing nomogram for continuous infusion intravenous naloxone. Ann Emerg Med 1986;15:566-70.

141 Hawton K, Simikin S, Deeks J. Co-proxamol and suicide: a study of national mortality statistics and local non-fatal self poisonings. BMJ 2003;326:1006-8

142 Lund-Jacobsen H. Cardio-respiratory toxicity of propoxyphene and norpropoxyphene in conscious rabbits. Acta Pharmacol Toxicol 1978;42:171-8.

143 Stork CM, Reed JT, Fine K, et al. Propoxyphene-induced wide QRS complex dysrhythmia responsive to sodium bicarbonate-a case report. J Toxicol Clin Toxicol 1995; 33:179-83.

144 Hojer J, Braehrendtz S, Gustafsson L. Benzodiazepine poisoning: experience of 702 admissions to an intensive care unit during a 14-year period. J Intern Med 1989;226:117-22.

145 Greenblatt DJ, Allen MD, Noel BJ. Acute overdose with benzodiazepine derivatives. Clin Pharmacol Ther 1977;21:497-514.

146 Serfaty M, Masterton G. Fatal poisonings attributed to benzodiazepines in Britain during the 1980s. Br J Psychiatry 1993;163:386-93.

147 Martens F, Koppel C, lbe K, et al. Clinical experience with the benzodiazepine antagonist flumazenil in suspected benzodiazepine or ethanol poisoning. J Toxicol Clin Toxicol 1990;28:341-56.

148 Haverkos GP, DiSalvo RP, Imhoff TE. Fatal seizures after flumazenil administration in a patient with a mixed drug overdose. Ann Pharmacother 1994:28:1347-9.

149 Herd B, Clarke F Herd B, Clarke F. Complete heart block after flumazenil. Hum Exp Toxicol 1991;10:289.

150 Geller E, Crome P, Schaller MD, et al. Risks and benefits of therapy with flumazenil (Anexate) in mixed drug intoxications. Eur Neurol 1991;31:241-50.

151 Amerin R, Leishman B, Bentzinger C, et al. Flumazenil in benzodiazepine antagonism. Actions and clinical use in intoxications and anaesthesiology. Med Toxicol Adverse Drug Exp 1987;2:41 1-29.

152 Spivey WH. Flumazenil and seizures: analysis of 43 cases. Clin Ther 1992; 14:292-305.

153 Frommer DA, Kulig KW, Marx JA, et al. Tricyclic antidepressant overdose. A review. JAMA 1987;257:521-6.

154 Callaham M, Kassel D. Epidemiology of fatal tricyclic antidepressant ingestion: implications for management. Ann Emerg Med 1985;14:1-9.

155 Shannon M. Duration of QRS disturbances after severe tricyclic antidepressant intoxication. J Toxicol Clin Toxicol 1992;30:377-86.

156 Liebelt EL, Francis PD. Cyclic Antidepressants. In: Goldfrank LR, Flomenbaum NE, Lewin NA, et al. Goldfranks toxicologic emergencies. 7th ed. New York: McGraw-Hill, 2002:847-64.

157 Henry JA. Epidemiology and relative toxicity of antidepressant drugs in overdose. Drug Saf 1997;16:374-90.

158 Sasyniuk BI, Jhamandas V. Mechanism of reversal of toxic effects of amitriptyline on cardiac Purkinje fibers by sodium bicarbonate. J Pharmacol Exp Ther 1984;231:387-94.

159 Pellinen TJ, Farkkila M, Heikkila J, et al. Electrocardiographic and clinical features of tricyclic antidepressant intoxication. A survey of 88 cases and outlines of therapy. Ann Clin Res 1987;19:12-17.

160 Shannon MW, Merola J, Lovejoy FH Jr. Hypotension in severe tricyclic antidepressant overdose. Am J Emerg Med 1988;6:439-42.
161 Pentel PR, Benowitz NL. Tricyclic antidepressant poisoning. Management of arrhythmias. Med Toxicol 1986;1:101-21.

162 Boehnert MT, Lovejoy FH Jr. Value of the QRS duration versus the serum drug level in predicting seizures and ventricular arrhythmias after an acute overdose of tricyclic antidepressants. N Engl J Med 1985;313:474-9.

163 Caravati EM, Bossart PJ. Demographic and electrocardiographic factors associated with severe tricyclic antidepressant toxicity. J Toxicol Clin Toxicol 1991:29:31-43.

164 Liebelt EL, Francis PD, Woolf AD. ECG lead aVR versus QRS interval in predicting seizures and arrhythmias in acute tricyclic antidepressant toxicity. Ann Emerg Med 1995;26:195-201.

165 Hoffman JR. Overdose with cardiotherapeutic agents. Geriatrics 1983;38:51-65.

166 Levitt MA, Sullivan JB, Owens SM, et al. Amitriptyline plasma protein binding: effect of plasma $\mathrm{pH}$ and relevance to clinical overdose. Am J Emerg Med 1986;4:121-5.

167 McCabe JL, Cobaugh DJ, Menegazzi JJ, et al. Experimental tricyclic antidepressant toxicity: a randomized, controlled comparison of hypertonic saline solution, sodium bicarbonate, and hyperventilation. Ann Emerg Med 1998;32:329-33.

168 Sasyniuk BI, Jhamandas V, Valois M. Experimental amitriptyline intoxication: treatment of cardiac toxicity with sodium bicarbonate. Ann Emerg Med 1986;15:1052-9

169 Orr DAK, Bramble MG. Tricyclic antideressant poisoning and prolonged external cardiac massage during asystole. BMJ 1981;283:1107-8

170 Southall DP, Kilpatrick SM. Imipramine poisoning: survival of a child after prolonged cardiac massage. BMJ 1974;4:508

171 Beaubein AR, Carpenter DC, Mathieu FL. Antagonism of imipramine poisoning by anticonvulsants in the rat. Toxicol Appl Pharmacol 1976;38:1-6.

172 Borys DJ, Setzer SC, Ling $\sqcup$, et al. Acute fluoxetine overdose: a report of 234 cases. Am J Emerg Med 1992;10:115-20.

173 Braitberg G, Curry SC. Seizure after isolated fluoxetine overdose. Ann Emerg Med 1995;26:234-7.

174 Graudins A, Vossler C, Wang R. Fluoxetine-induced cardiotoxicity with response to bicarbonate therapy. Am J Emerg Med 1997; 15:501-3.

175 Johnsen CR, Hoejlyng N. Hyponatremia following acute overdose with paroxetine. Int J Clin Pharmacol Ther 1998;36:333-5.

176 Personne M, Sjoberg G, Persson H. Citalopram overdose-review of cases treated in Swedish hospitals. J Toxicol Clin Toxicol 1997;35:237-40.

177 White CM, Hailey RA, Levin GM, et al. Seizure resulting from a venlafaxine overdose. Ann Pharmacother 1997;31:178-80.

178 Zhalkovsky B, Walker D, Bourgeois JA. Seizure activity and enzyme elevations after venlafaxine overdose. J Clin Psychopharmacol 1997:17:490-1.

179 Banham NDG. Fatal venlafaxine overdose. Med J Aust 1998;169:445-8.

180 Blythe D, Hackett LP. Cardiovascular and neurological toxicity of venlafaxine. Hum Exp Toxicol 1999; 18:309-13.

181 Whyte IM, Dawson AH, Buckley NA. Relative toxicity of venlafaxine and selective serotonin reuptake inhibitors in overdose compared to tricyclic antidepressants. Q J Med 2003;96:369-74.

182 Chan BS, Graudins A, Whyte IM, et al. Serotonin syndrome resulting from drug interactions. Med J Aust 1998;169:523-5.

183 Daniels RJ. Serotonin syndrome due to venlafaxine overdose. J Accid Emerg Med 1998;15:333-7.

184 Martin TG. Serotonin syndrome. Ann Emerg Med 1996;28:520-6.

185 Kolecki P. Isolated venlafaxine-induced serotonin syndrome. J Emerg Med 1997;15:491-3.

186 Rosebush PI, Margetts P, Mazurek MF. Serotonin syndrome as a result of clomipramine monotherapy. J Clin Psychopharmacother 1999; 19:285-7

187 Stork CM. Serotonin reuptake inhibitors and atypical antidepressants. In: Goldfrank LR, Flomenbaum NE, Lewin NA, et al. Goldfranks toxicologic emergencies. 7th ed. New York: McGraw-Hill, 2002:868-9.

188 Graudins A, Stearman A, Chan B. Treatment of the serotonin syndrome with cyproheptadine. J Emerg Med 1998;16:615-19.

189 Hollander JE, Hoffman RS, Gennis P, et al. Prospective multicenter evaluation of cocaine-associated chest pain. Acad Emerg Med 1994;1:330-9.

190 Richard A Lange MD, L David Hillis MD. Cardiovascular complications of cocaine use. N Engl J Med 2001;345:351-8

191 Mittleman MA, Mintzer D, Maclure M, et al. Triggering of myocardial infarction by cocaine. Circulation 1999;99:2737-41.

192 Lange RA, Cigarroa RG, Yancy CW Jr, et al. Cocaine-induced coronaryartery vasoconstriction. N Engl J Med 1989;321:1557-62

193 Flores ED, Lange RA, Cigarroa RG, et al. Effect of cocaine on coronary artery dimensions in atherosclerotic coronary artery disease: enhanced vasoconstriction at sites of significant stenoses. J Am Coll Cardiol 1990;16:74-9.

194 Moliterno DJ, Willard JE, Lange RA, et al. Coronary-artery vasoconstriction induced by cocaine, cigarette smoking, or both. N Engl J Med 1994;330:454-9.

195 Rezkalla SH, Mazza JJ, Kloner RA, et al. Effects of cocaine on human platelets in healthy subjects. Am J Cardiol 1993;72:243-6.

196 Kugelmass AD, Oda A, Monahan K, et al. Activation of human platelets by cocaine. Circulation 1993;88:876-83.

197 Rinder HM, Ault KA, Jatlow Pl, et al. Platelet alpha-granule release in cocaine users. Circulation 1994;90:1162-7. 
198 Kolodgie FD, Virmani R, Cornhill JF, et al. Increase in atherosclerosis and adventitial mast cells in cocaine abusers: an alternative mechanism of cocaine-associated coronary vasospasm and thrombosis. J Am Coll Cardiol $1991 ; 17: 1553-60$

199 Kolodgie FD, Wilson PS, Mergner WJ, et al. Cocaine-induced increase in the permeability function of human vascular endothelial cell monolayers. Exp Mol Pathol 1999;66:109-22.

200 Gan X, Zhang L, Berger O, et al. Cocaine enhances brain endothelial adhesion molecules and leukocyte migration. Clin Immunol 1999:91:68-76.

201 Gitter MJ, Goldsmith SR, Dunbar DN, et al. Cocaine and chest pain: clinical features and outcome of patients hospitalized to rule out myocardial infarction. Ann Intern Med 1991;115:277-82.
202 Hollander JE, Levitt MA, Young GP, et al. Effect of recent cocaine use on the specificity of cardiac markers for diagnosis of acute myocardial infarction. Am Heart J 1998; 135:245-52

203 Lange RA, Cigarroa RG, Flores ED, et al. Potentiation of cocaine-induced coronary vasoconstriction by beta-adrenergic blockade. Ann Intern Med 1990:112:897-903.

204 Guidelines 2000 for cardiopulmonary resuscitation and emergency cardiovascular care. 8. Advanced challenges in resuscitation. 2. Toxicology in ECC. Circulation 2000;102:1-223.

205 ACLS. Guidelines 2000 for cardiopulmonary resuscitation and emergency cardiovascular care. 6. Advanced cardiovascular life support. 1. Introduction to ACLS 2000: overview of recommended changes in ACLS from the Guidelines 2000 conference, Circulation 2000;102:1-86.

\section{IMAGES IN MEDICINE.}

\section{Scimitar syndrome (congenital pulmonary venolobar syndrome)}

A

19 year old woman was referred for left sided chest pain. There were no other symptoms but a day earlier she had been lifting heavy boxes. Her examination was entirely normal except for left sided localised chest wall tenderness. A clinical diagnosis of musculoskeletal chest pain was made. Her ECG and the rest of the baseline laboratory tests were normal. Her chest radiograph (fig l (A)) shows a small right hemithorax and an anomalous pulmonary vein on the right side (arrows). The magnetic resonance imaging scan (fig $\mathrm{l}$ (B)) shows that the anomalous vein (arrows) is draining into the right atrium (RA). The hypoplastic right lung and anomalous pulmonary vein confirmed that she had congenital pulmonary venolobar syndrome also known as scimitar syndrome. The name scimitar comes from the anomalous pulmonary vein that courses along the right cardiac margin as a curvilinear shadow and is said to resemble a "scimitar," or Turkish sword. The anomalous venous return is usually to the inferior vena cava but it can also be to the portal vein, a hepatic vein, or the right atrium. Presentation and clinical course depends on the size of the shunt and varies from heart failure in infancy to asymptomatic adulthood. About $25 \%$ of the patients have associated congenital heart disease, most commonly septal defects. Our patient did not have any such defect. She remained well and active and did not need any further intervention.

A Khan, N J Ring, P D Hughes Department of Respiratory and General Medicine, Derriford Hospital, Plymouth, UK

Correspondence to: Dr A Khan, Department of Respiratory and General Medicine, Derriford Hospital, Plymouth PL6 8DH, UK; Ayaz.khan@phnt.swest.nhs.uk
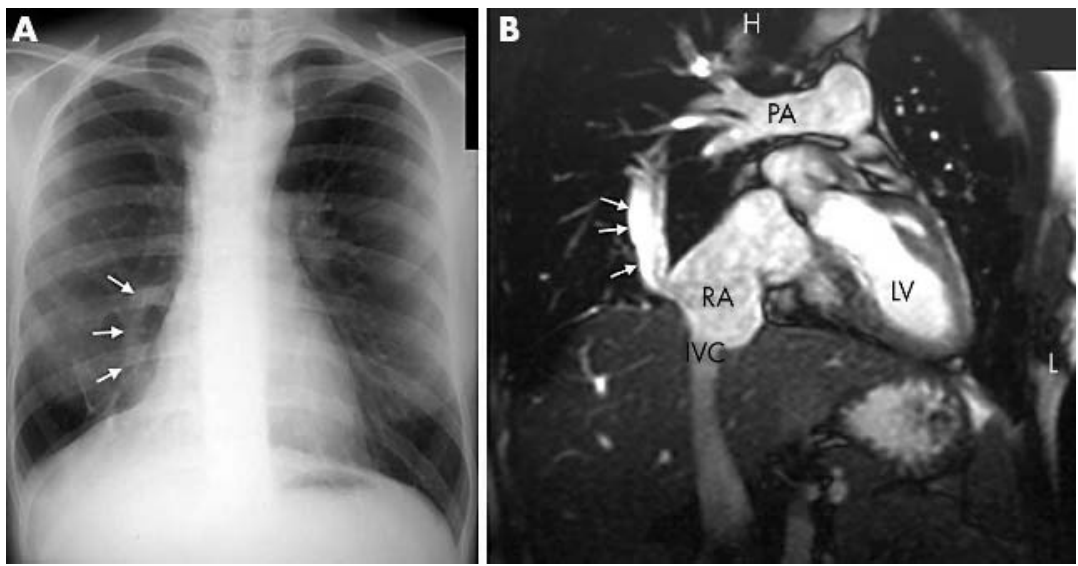

Figure 1 (A) Chest radiograph. (B) Magnetic resonance imaging scan. RA, right atrium; LV, left ventricle; PA, pulmonary artery; IVC, inferior vena cava. 